\title{
1. Introduction: globalisation and the manufacturing revolution
}

The twenty-first century is becoming an era of profound societal and economic change. Globalisation has reduced its pace after the financial crisis, at least in terms of global trade of physical goods and services. However, industries are pursuing the structural changes implied by the rising extent of the market brought about by globalisation. Firms sell in global markets and ally with competitors to realise the $\mathrm{R} \& \mathrm{D}$ of specific product components or product varieties, while also creating new forms of market interactions thanks to new digital technologies. They can continuously interact with consumers to identify their needs, propose specific solutions and learn from consumers providing their experience with products on online forums.

Global value chains are changing. First, the trend in the last few years has been of reshoring or back shoring - a return of previously outsourced production phases to the home country or to the main production sites. Second, with the hyper connection induced by the fourth industrial revolution (see Chapter 3) offices and divisions even in faraway distance can be managed more efficiently and with lower volumes of flows of parts and goods, which are partly replaced by data flows.

Figure 1.1 shows world export of physical goods, in the period 1980 to 2016. Globalisation appears clearly, in the sense of exponential rise of global trade in the 1990s and up to the financial crisis of 2008. This sustained growth came to a halt during the financial crisis and does not appear to be starting again. However, firms continue operating on a global basis. Figure 1.2 shows the transformation of these global operations: they have become essentially digital, in that 'trade' appears to increasingly consist of data, and digital globalisation is happening at an extremely rapid pace.

Digital globalisation is the result of the fourth industrial revolution, induced by the technological progress that is taking place in many scientific and technological fields, and primarily in the 


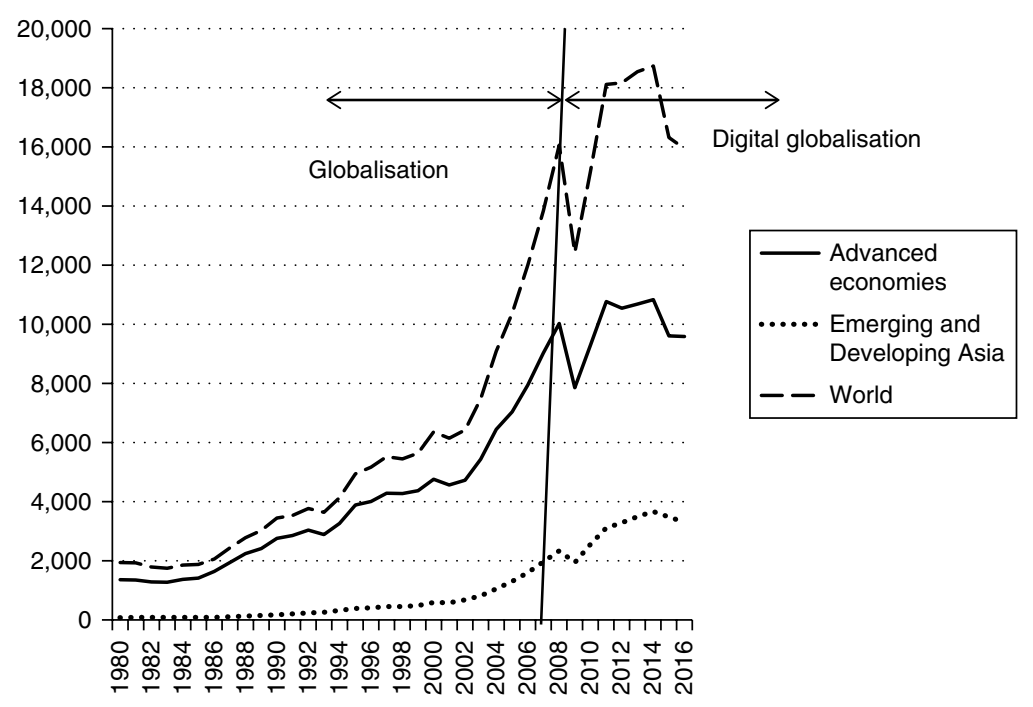

Source: IMF (2017) Data Mapper, available at http://www.imf.org/externalldata mapper/datasets, accessed 1 April 2017.

\section{Figure 1.1 Export of goods, annual, billion US \$}

evolution of ICTs into hyperconnected systems. Internet essentially started to diffuse in the 1990s, and is now pervasive and omnipresent in the everyday working, leisure or family lives of most people on the planet.

This book aims at analysing the structural transformations brought about by the fourth industrial revolution - particularly the advent of the digital globalisation and its implications for the structure and dynamics of industry - so as to outline what type of industrial policy or industrial strategies are needed in this era of rapid and substantial transformations. We propose the concept of comprehensive industrial policy, in the sense of policy actions considering the complexity of structural changes, which involve not only industry per se but also institutions (regulation) and social and education policies (to favour the participation of all citizens in the development process). We explain the concept and also provide an example of implementation of such a comprehensive industrial policy, at regional level, in the Emilia-Romagna (ER) region in Italy. 


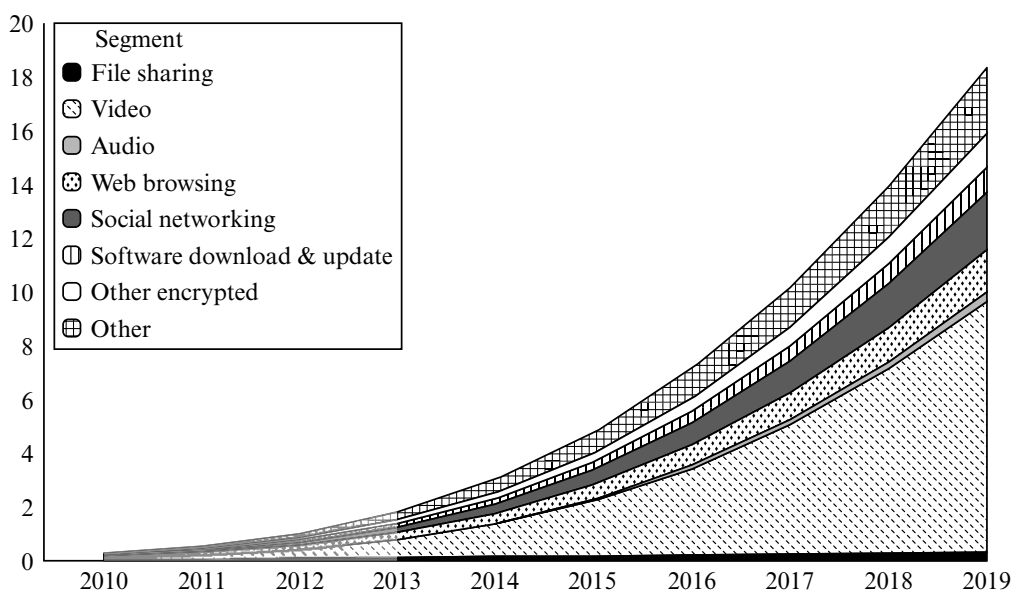

Source: Ericsson (n.d.) 'Mobile technology trends: traffic by application category. Mobile video traffic is becoming increasingly dominant', available at https://www.ericsson. com/en/mobility-report/mobile-traffic-by-application-category, accessed 24 January 2018.

Figure 1.2 Mobile data traffic by application type (monthly exabytes)

\section{MANUFACTURING TRANSITION AND INDUSTRIAL POLICY}

As in previous research on industrial policy (Bianchi and Labory, 2006, 2009, 2011a, 2011b) we define industry as the capacity to organise production in correspondence to market needs, so that industry can be in all sectors, from agricultural to manufacturing and services. In the past, industry studies and industrial economics have tended to confine industry to the manufacturing sector, following the famous division introduced by Fisher in 1935 into the three sectors. However, economic, social and technological developments have made this distinction increasingly outdated, especially in the last few decades where the three sectors have become progressively intertwined. Services and manufacturing are intersecting, since products are bundled with services; the agricultural sector has been deeply transforming and the adoption of new technologies - including the digital ones but not only these - is making this sector not so much 'primary' in the sense that the transformation operated on 
the product is substantial (making tomatoes more tasty and more germ-resistant, or other agricultural products that are transformed by bio- and other technologies to make food healthy and even curing diseases).

Given this concept of industry we define industrial policy in a broad manner, as a set of actions aimed at favouring structural changes in industries and orientating industrial development in specific directions. Such actions regard innovation, trade, intellectual property rights and antitrust; they also regard labour, because firms cannot upgrade or be created if they do not find the human capital they need for their operations. Looking at providing appropriate human capital means considering social policies, labour contracts and measures to favour the participation in the labour force. It also means considering education and training, because they determine the types of skills people will be able to develop.

We argue that industrial policies are particularly needed when the economy experiences deep transformations, such as industrial revolutions. The advent of digital globalisation is primarily driven by the technological progress induced by the fourth industrial revolution, but we believe that industrial revolutions are the result of complex transformations of the economy, the society and culture. Hence the first part of this book is dedicated to the analysis of the fourth industrial revolution, outlining its main features and implications through a comparative analysis with the first industrial revolutions. The comparative and historical analysis of the first industrial revolutions outlines that industrial revolutions represent transitions between manufacturing regimes, that they are complex and require broad industrial policies.

The analysis of the fourth industrial revolution outlines the structural changes arising in industries, as described by firm managers, scientists and consultants, as well as the literature on the fourth industrial revolution. It raises the need for new industrial policies, which are discussed in the rest of the book. Major science and technological developments are indeed taking place, in different fields including high power computing, artificial intelligence, robotics, new materials, genomics and nanotechnologies. These developments will have profound impact on industries not only because of technological progress in single scientific fields, but also because they are converging to enable new products and new production processes. 
We outline two aspects of these industrial policy actions for the manufacturing revolution: first, the role of territories in multilevel governance processes; and second, the key role of training and education, which has to be rethought and adapted. In this sense industrial policy has to be comprehensive (keeping together the ecosystem).

Bianchi and Labory (2011a) argued that globalisation was, at the turn of the century, inducing substantial structural changes in industry that were calling for industrial policy to promote these changes along desired development paths. Globalisation was intended as the growth of world trade and foreign direct investments, which accelerated in the 1990s following the major political upheaval of the end of communism and the transition of many countries into market economies, as well as the growing importance of emerging economies, the so-called BRIC countries. In fact, industrial policy has returned worldwide as an essential policy in times of deep structural transformation of the economy.

In the meantime, however, other disruptive changes have been progressively taking place, in the fields of science and technological developments, leading to what many experts and scholars have come to name the fourth industrial revolution.

This industrial revolution is not easy to characterise because it consists of many scientific and technological developments: in genomics, biotechnologies, nanotechnologies, computer and data sciences, artificial intelligence, robotics, sensors and connecting technologies and so on. Many experts argue that what is new in this fourth industrial revolution is both the speed of change and the convergence of scientific fields and technologies in the production of new solutions, new products and new processes. However, as will be claimed in the following chapters of this book, the first three industrial revolutions had the same characteristics. Technological changes take place over a long time period with some sub-periods of acceleration, such as the 1960s during the third industrial revolution; technologies converged even in previous revolutions. The best example of this pattern is probably the automobile, which was developed as a product at the beginning of the twentieth century (during the second industrial revolution), using the new combustion engine, new steel, new rubber and other chemical developments.

Some economic historians have characterised industrial revolutions 
by the changing technological paradigm they imply: see Freeman and Lourça (2001) concerning the first three industrial revolutions. However, industrial revolutions are not only about technological developments. They constitute revolutions because they imply changes in manufacturing regimes, determined by socio-economic and political conditions and having in turn large impact on the socio-economic and political conditions. Manufacturing regimes are intended as prevailing production processes, which are methods or technologies of production. The following chapters will show that each industrial revolution is associated with a particular manufacturing regime. It does not mean that all firms in all sectors adopt the same production organisation but there are main features of their production processes that are common; for instance, the division into elementary tasks performed by low-skilled workers under time constraint in the mass production system.

The fourth industrial revolution is having a major impact on industry and societies primarily because of what has been called its raw material: data. New technologies are allowing hyperconnection of people on a global basis, but also of people with machines and between machines (the Internet of Things, IoT). Global data flows are booming, raining new regulatory issues: first, a few very large firms are accumulating enormous amounts of data on individuals and base their market power on this (online platforms, see Chapter 4). Besides privacy issues, there are new antitrust issues.

\section{GLOBALISATION AFTER THE FINANCIAL CRISIS}

Real GDP growth has been claimed to be too slow, for too long by the IMF (2016). Figure 1.3 indeed shows the important recession induced by the financial crisis, after which real GDP growth worldwide did not recover the rates prevailing prior to the crisis. World growth was driven by the rapid expansion of emerging and developing countries over the period 2001 to 2008 , which is still true after the crisis but with much slower rate. Advanced countries' growth has tended to stagnate or even reduce.

Figures 1.4 and 1.5 add comparisons and show that while all BRIC countries drove global GDP growth in the period prior to the crisis, this is no longer the case, since Brazil and the Russian Federation 


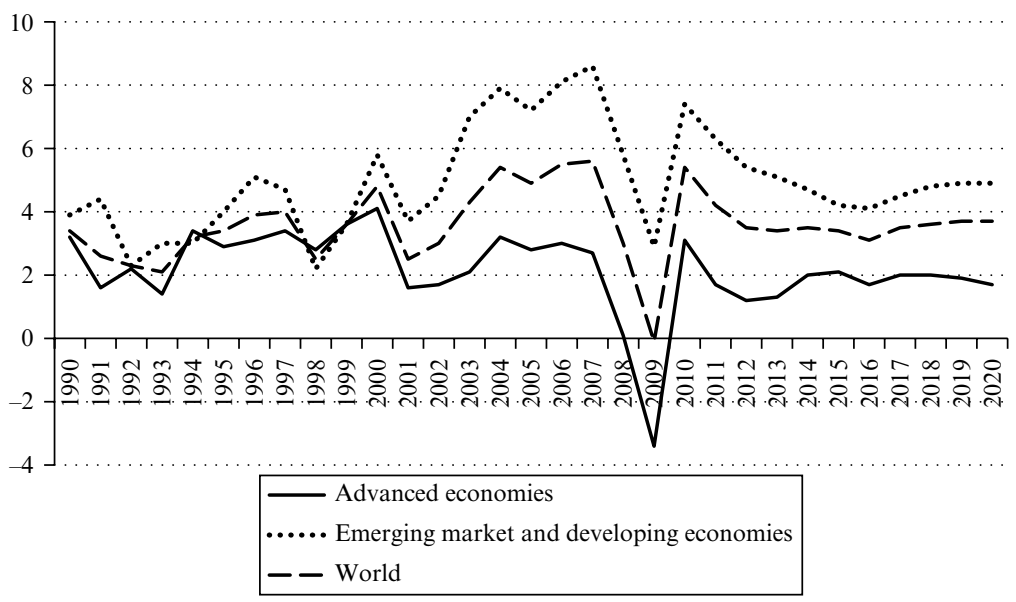

Source: IMF (2017) Data Mapper, available at http://www.imf.org/externalldata mapper/datasets, accessed 1 April 2017.

Figure 1.3 Real GDP growth (annual percentage change)

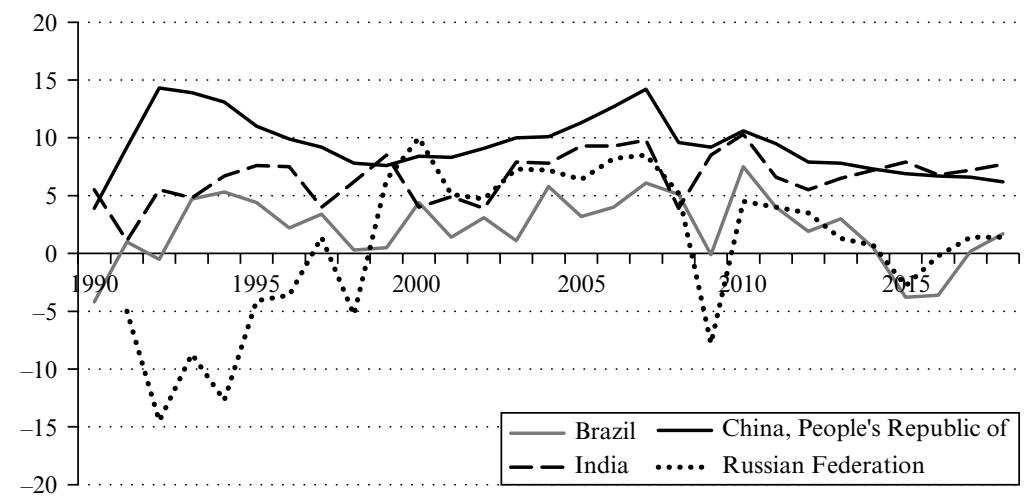

Source: IMF (2017) Data Mapper, available at http://www.imf.org/externalldata mapper/datasets, accessed 1 April 2017.

Figure 1.4 Real GDP growth in BRIC countries, 1990 to 2018 


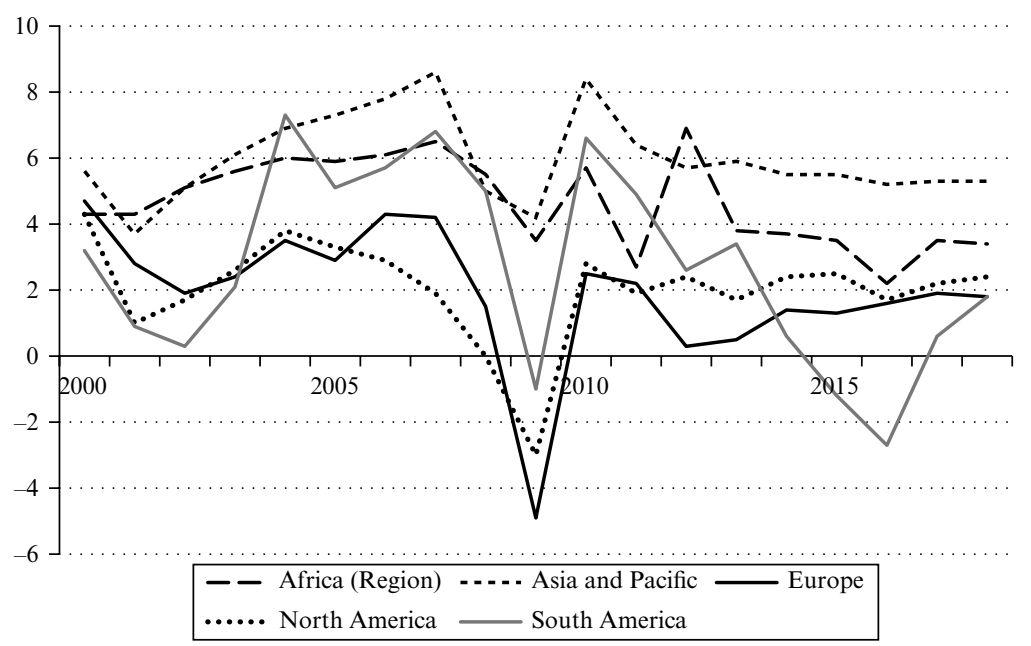

Source: IMF (2017) Data Mapper, available at http://www.imf.org/externalldata mapper/datasets, accessed 1 April 2017.

Figure 1.5 Real GDP growth by world regions, 1990 to 2018

have seen their growth sharply decline. The picture that clearly emerges now is a strong lead of Asia relative to other continents and groups of countries.

Europe and North America seem to stabilise around moderate growth rates, at about 2 per cent, while growth in Asia stabilises between 5 per cent and 6 per cent. The worst group of countries in terms of real GDP growth is South America.

Figure 1.3 shows that there does not seem to be a recovery of globalisation, in the sense of growing trade flows, after the financial crisis. To the contrary trade flows appear to have remained stable in the last decade, since the volume of exports and imports in the world are about at the same level in 2007 and 2016. This hides a slight decline in advanced countries compensated by a slight increase in emerging and developing Asia.

The end of the bipolar world characterised by the dominance of the Western and the Eastern blocks in the 1990s has therefore paved the way to a multipolar world, where new powers were emerging, particularly the BRIC countries, and among them, China. In the twenty-first century and particularly after the financial crisis the 
world is characterised by the continued dominance of the USA, although declining, and the strong rise of Asia, driven by China. Europe is still an important economic block, and the recent compacting of EU countries as a reaction to Brexit is welcome. The 27 countries remaining in the Union are indeed showing increasing collaboration and cooperation in front of the fear of disaggregation induced by the exit of the UK from the Union and the rise of populist movements.

After the financial crisis a new phase of the global economy has started, characterised by a moderation of globalisation, since global trade flows are no longer rising at sustained rates, and an increasing importance and leadership of the Asian continent, particularly China.

The importance of the Asian block is shown in the following figures. China is the first country in terms of contribution to manufacturing value added, both in levels and in dynamics (fastest growth). The USA and EU28 are second to China in terms of levels

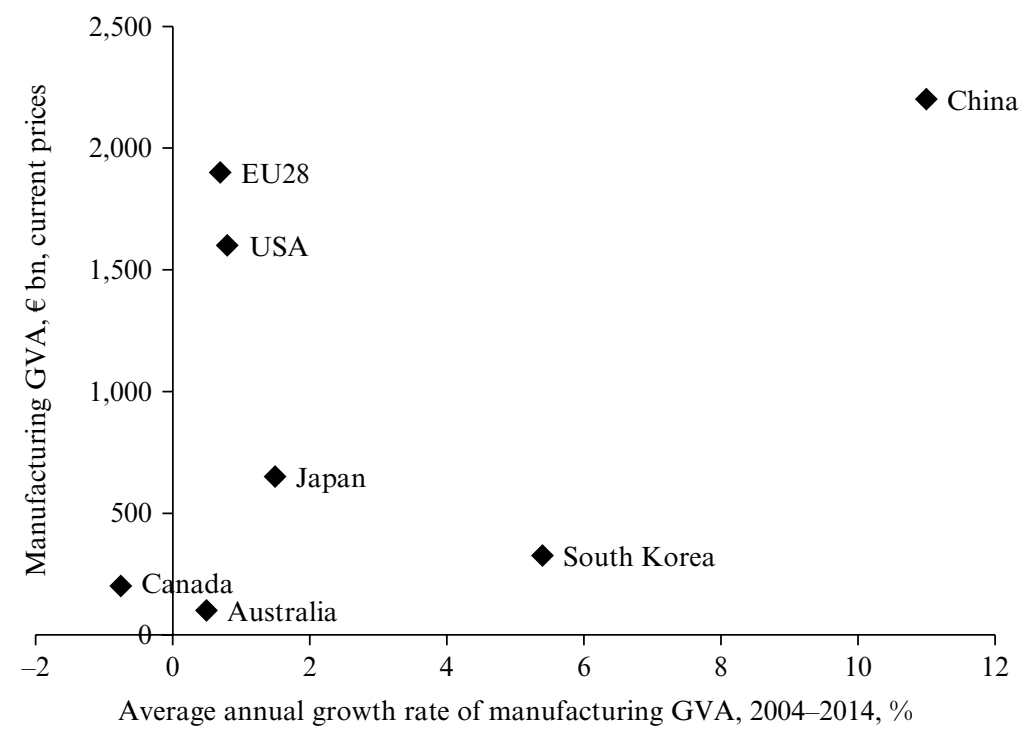

Source: European Commission (2016a, p. 106).

Figure 1.6 Manufacturing-gross value added and annual growth rate of gross value added, 2004-2014 
of value added in manufacturing, but the annual growth is much slower than that of China.

Chapter 3 provides other data on the strength of manufacturing and the positioning of countries in the fourth industrial revolution, showing that Asian countries and particularly China are strongly investing in $\mathrm{R} \& \mathrm{D}$ and in skills, so that the situation outlined above is likely to strengthen.

However, before going further into the fourth industrial revolution another aspect of the restructuring of the global economy has to be outlined: while global flows of goods appear to be stagnating in the last decade, the striking feature is that another aspect of globalisation is exponentially growing, namely global flows of data.

\section{GLOBALISATION OF THE EXCHANGE DATA WORLDWIDE}

Information on the volume of data exchanged from mobile phones, computers and other communicating devices show us that globalisation has not slowed down, but rather it has taken a different form.

It has to be noted that despite the substantial development of the use of computers, smartphones, for communication and exchange of data worldwide, statistical offices do not provide statistics on this aspect. We had to look for private sources of data, the reliability of which might not be as strong, but they suggest at least that some more systematic data collection and analysis by national and international statistical offices would be useful.

CISCO (2017) provides some statistics on global mobile data since 2011, with some forecasts over the period 2016 to 2021. The result is that mobile data traffic has grown 18 -fold over the period 2011 to 2016.

Global flows of mobile data are expected to exponentially increase in the future, from seven to 49 exabytes per month. Looking at the different regions, the fastest growth is expected in Asia, which will account for almost half global data traffic by 2021 . Hence even in terms of this indicator Asia will consolidate its worldwide lead. In addition, the Middle East and Africa will experience very strong growth in the next five years.

The breakdown of global data traffic according to devices is also interesting (Figure 1.8). 


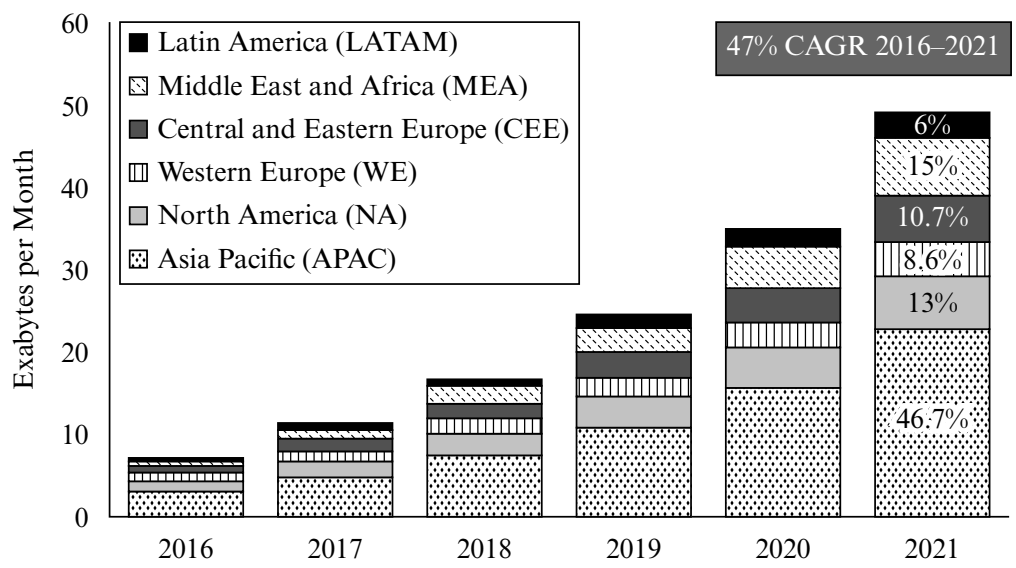

Source: $\operatorname{CISCO}(2017$, p.5).

Figure 1.7 Global mobile data traffic forecast by region

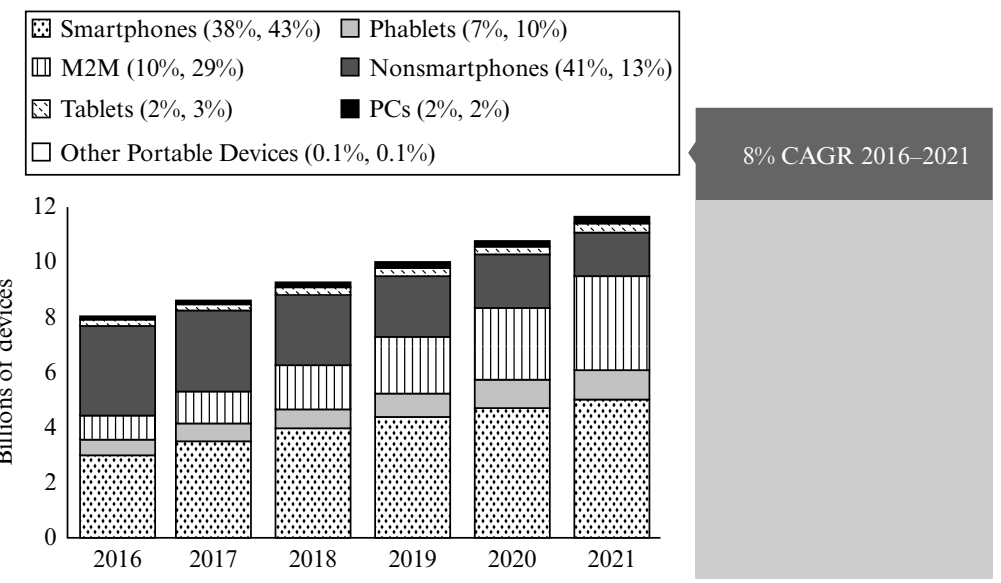

Note: Figures in parentheses refer to 2016, 2021 device share.

Source: $\operatorname{CISCO}(2017, p .6)$.

Figure 1.8 Global mobile devices and connection growth 
Smartphones are expected to continue being the main source of global data traffic in the next five years, reaching 43 per cent in 2021. However, the interesting trend is that of Machine-to-Machine (M2M) devices, which will constantly grow in the next five years and account for about a third of mobile data traffic by 2021. These devices consist of various wired and wireless technologies that enable different machines of the same type other than smartphones, tablets and wearables to connect with each other so that assets, devices and machines can remotely operate, without human assistance. M2M is in fact the Internet-of-Things (IoT), namely the key feature of the fourth industrial revolution, as will be shown in Chapter 3. Examples include GPS systems in cars, medical applications making patient health record and status more readily available, home and office security and automation, as well as the industrial Internet.

Overall, global mobile data traffic is expected to rise sevenfold between 2016 and 2021, and by 2021 almost three quarters of all devices connected to the mobile network will be smart devices. This outlook is coherent with Figure 1.2, showing the growth in global flows of data between 2010 and 2019, data provided by Ericsson (n.d.).

It appears therefore that while the flow of physical goods and capital appears to have come to a halt in the last decade, globalisation has not stopped but is taking another form: it is becoming digital (leaving aside financial flows, which are substantial and actually an increasing share of these flows are digital too).

The next chapters will provide a reflection on what this 'digital globalisation' means for economies and for industrial development policies. The second chapter analyses the characteristics of the first three industrial revolutions, in order to highlight to what extent we are indeed in the middle of a fourth industrial revolution. The importance of innovations and technological progress is stressed, but, moving beyond technological determinism, the cultural, social and political factors favouring industrial revolutions and their retroactions on structural changes are highlighted. The crucial importance of the evolution of education systems during these revolutions is also outlined.

The third chapter focuses on the fourth industrial revolution. The technological drivers are examined, and their combined effects together with other factors such as globalisation are examined. The result is that the fourth industrial revolution offers great opportunity 
to resolve the current global societal challenges, such as demographic trends of population growth and population ageing, rapid and wide urbanisation, as well as preservation of ecosystems and climate change. However, this opportunity will be realised only if the large changes induced by the scientific/technical/economic engine are accompanied by appropriate ethical/cultural/social changes, which have been called for, perhaps without a complete awareness, in the search for resilience and sustainability in policymaking worldwide. For this purpose, addressing the complexity is essential, keeping in mind that complexity comes from the Latin word complexus, meaning related, woven together, intertwined. In particular the resolution of this complexity and the needed ethical, cultural and social metamorphosis call for a new role of territories, which is examined in more depth in Chapter 5, with the example of the Italian Emilia-Romagna Region, whose industrial policy one of the authors, Patrizio Bianchi, has contributed to define.

While Chapter 3 focuses on the supply side, the fourth chapter analyses the deep transformation of the demand side of markets. The fourth industrial revolution is indeed also a revolution in the interaction between consumers and producers, allowed by the development of platforms, especially online ones. They allow new businesses to be created, such as Uber and Airbnb, and they have deep implications even for incumbent firms in existing industries. The way producers interact with consumers is changing, as well as the nature of products, which services' content become essential from a strategic point of view. Many manufacturers indeed argue that they are now selling solutions rather than products. Competition intensifies, because even existing businesses can be challenged by new entrants building a new platform, a new variety of the product that serves specific needs and can substantially grow if the new entrant is able to build a new community of consumers around it.

Platforms raise new issues of competition policy. We argue that they raise issues of product and services regulation, as well as privacy and market or political power due to the enormous amount of personal data platforms are able to collect and analyse, while consumers are not always aware of the personal information they reveal through their use of these new online markets and apps. Oil is no longer the strategic raw material, data are; firms such as Google, Amazon, Facebook and Apple have been claimed to have the monopolistic dominance that Standard Oil had in the nineteenth century. ${ }^{1}$ 
The fourth industrial revolution has therefore a deep impact on industries, on both the supply and the demand sides. The roots of the structural changes implied in industrial revolutions, namely changes in manufacturing regimes, have to be analysed in order to comprehend this complexity. Each industrial revolution is associated with a particular manufacturing regime, the factory system in the first revolution, mass production in the second, flexible production in the third and mass customisation in the fourth (see also Bianchi and Labory, 2017). These transitions call for comprehensive industrial policy that is analysed and illustrated in Chapter 5. The ER region has indeed shifted from a manufacturing regime based on industrial districts in the 1980 s, to a regional innovation system in the 1990s and the first decade of the twenty-first century, to a hub in the mass customised production system since 2010 . The industrial policy implemented in the region has been comprehensive, aiming at favouring adaptation and adaptability, by coherently defining actions promoting innovation and adoption of new technologies, adjustment in human capital, and provision of appropriate infrastructure.

\section{NOTE}

1. The Economist (2017), 'The world's most valuable resource is no longer oil, but data', 6 May, available at https://www.economist.com/news/leaders/21721656-dataeconomy-demands-new-approach-antitrust-rules-worlds-most-valuable-resource, accessed 25 January 2018. 